\title{
Different responses of heterogeneous graft presentations in bone reconstructions during sinus lift elevation surgery: an immunolabeling and histomorphometric study performed in rabbits
}

\author{
Natália Barbosa de Siqueira ${ }^{1} \wedge$, Ana Cláudia Ervolino da Silva ${ }^{1} \wedge$, Rodrigo dos Santos Pereira ${ }^{2}$, \\ Eduardo Hochuli-Vieira ${ }^{3} \wedge$, Paulo Noronha Lisboa-Filho ${ }^{4}$, Ciro Borges Duailibe de Deus ${ }^{1 \wedge}$, \\ Roberta Okamoto $^{1 \wedge}$
}

${ }^{1}$ Araçatuba Dental School, São Paulo State University Júlio de Mesquita Filho, Sao Paulo, Brazil; ªrande Rio University, UNIGRANRIO, Duque de Caxias, Brazil; ${ }^{3}$ Araraquara Dental School, São Paulo State University Júlio de Mesquita Filho, Sao Paulo, Brazil; ${ }^{4}$ Bauru School of Sciences, São Paulo State University Júlio de Mesquita Filho, Sao Paulo, Brazil

Contributions: (I) Conception and design: RDS Pereira, R Okamoto; (II) Administrative support: E Hochuli-Vieira, PN Lisboa-Filho, R Okamoto; (III) Provision of study materials or patients: RDS Pereira, E Hochuli-Vieira, PN Lisboa-Filho, R Okamoto; (IV) Collection and assembly of data: NB de Siqueira, ACED Silva, CB Duailibe de Deus; (V) Data analysis and interpretation: NB de Siqueira, R Okamoto; (VI) Manuscript writing: All authors; (VII) Final approval of manuscript: All authors.

Correspondence to: Ana Cláudia Ervolino da Silva. Araçatuba Dental School, São Paulo State University Júlio de Mesquita Filho, Sao Paulo, Brazil. Email: anaervolino@hotmail.com.

Background: This study aims to analyze the process of bone formation, maturation and mineralization promoted by Cerabone ${ }^{\circledR}$ functionalization with raloxifene in rabbit sinus floor elevation, through immunohistochemical and histomorphometric analyses.

Methods: Twenty-four male rabbits had their maxillary sinuses filled. To access the sinus cavity a circular window with a diameter of $5 \mathrm{~mm}$ was made bilaterally to the midline of the nasal dorsum, the sinus membrane was detached and elevated using special curettes. Autogenous bone (G1), Cerabone ${ }^{\circledR}$ (G2), Cerabone ${ }^{\circledR}$ submitted to ultrasonic processing (G3), Cerabone ${ }^{\circledR}$ associated to raloxifene submitted to ultrasonic processing (G4) were used to fill the maxillary sinus, 14 and 42 days postoperatively. Immunohistochemical and histomorphometric analyses were performed at 14 and 42 days postoperatively.

Results: At 14 days postoperatively: the immunolabeling for vascular endothelial growth factor (VEGF) was moderate in groups G1, G3 and G4, while in group G2, the same protein was expressed in a mild way. The immunolabeling for alkaline phosphatase (ALP) was moderate in all experimental groups. Histomorphometric analysis showed a greater amount of newly formed bone in groups G1 (55.2\%) and G4 (50.1\%), which differed statistically from groups G2 (37.5\%) and G3 (38.2\%). At 42 days postoperatively: receptor activator of nuclear factor kappa-B ligand (RANKL) immunolabeling was slight in G1, intense in G2 and moderate in G3 and G4. The tartrate resistant acid phosphatase (TRAP) protein was slightly expressed in all experimental groups. The osteocalcin (OCN) protein was moderately expressed in the G1 group and intensely in the G2, G3 and G4 groups. As for the histomorphometric analysis, the greatest amount of neoformed bone was found in group G1 (83.5\%), followed by group G4 (75.0\%). Less neoformed bone was observed in G3 (56.7\%), followed by G2 (64.2\%). Statistical differences were observed between all experimental groups.

\footnotetext{
^ ORCID: Natália Barbosa de Siqueira, 0000-0003-0245-3639; Ana Cláudia Ervolino da Silva, 0000-0002-6592-0460; Rodrigo dos Santos Pereira, 0000-0003-2509-8633; Eduardo Hochuli-Vieira, 0000-0003-4040-9313; Paulo Noronha Lisboa-Filho, 0000-0002-7734-4069; Ciro Borges Duailibe de Deus, 0000-0001-9684-6956; Roberta Okamoto, 0000-0002-6773-6966.
} 
Conclusions: Better performance was observed in the group in which Cerabone was used in association with raloxifene (G4), with better bone formation responses compared to the experimental groups.

Keywords: Biocompatible materials; bone regeneration; bone substitutes; ultrasonic therapy

Received: 01 April 2021; Accepted: 06 December 2021; Published: 10 March 2022.

doi: $10.21037 /$ fomm-21-45

View this article at: https://dx.doi.org/10.21037/fomm-21-45

\section{Introduction}

Bone deficiency is one of the main limitations of rehabilitation treatment with osseointegrated dental implants, and the search for new methods that contribute to the gain of bone tissue in sites where implant installation is necessary is of great importance (1). In particular, vertical bone deficiency with pneumatization of the maxillary sinus, found in the posterior regions of the edentulous maxilla, is a challenge for implant dentists. Although autogenous grafting is considered the gold standard in bone reconstructions, the technique involves a second surgical approach and donor area morbidity, which can lead to the development of nerve damage, pain at the site, in addition to increased treatment costs, and is disadvantageous when compared to the use of biomaterials (2-5). Considering the relevance of this subject, it is evident that the search for developing methods to improve bone reconstructions by promoting angiogenesis and osteogenesis should be incessant.

The improvement of the properties of biomaterials through the process of functionalization of their surfaces with bioactive molecules that can promote favorable biological responses in tissue repair by direct action on bone cells is an alternative to be explored (6). It has been demonstrated that the addition of a selective modulator of estrogen receptors, raloxifene (Evista ${ }^{\circledR}$, Lilly, USA), to bone grafting materials can promote an effect at the cellular level, causing these favorable responses in the process of bone neoformation through osteoconduction (7). Allied to this is the use of ultrasonic processing, capable of promoting the synthesis of nanoparticles, where it is possible to homogenize substances, by means of ultrasonic waves, and promote chemical and physical modifications as a possibility to make this functionalization possible (8-11).

Cerabone ${ }^{\circledR}$ is a biomaterial formulated from the mineral phase of bovine bone that presents positive results for bone grafting purposes associated with oral rehabilitation (12-14), with properties such as surface morphology, porosity and composition similar to human bone. In addition, it has slow degradation, accelerated integration to the receptor site, absence of inflammatory reaction, adhesion and blood absorption, and ease of manipulation (15). Thus, when associated with bioactive molecules, such as the selective estrogen receptor modulator, which has the capacity to act directly on the osteoblasts of the receptor site, it can promote very promising effects resulting in an improvement of the reparational bone tissue $(6,16)$.

Thus, it is interesting to investigate the functionalization of a new biomaterial with superior characteristics to those available in the market, with a reduced cost, through the association between raloxifene and Cerabone ${ }^{\circledR}$ using ultrasonic processing. This study aims to analyze the process of bone formation, maturation and mineralization promoted by the functionalization of Cerabone ${ }^{\circledR}$ to raloxifene in rabbit sinus floor elevation, through immunohistochemical and histomorphometric analysis.

We present the following article in accordance with the ARRIVE reporting checklist (available at https://fomm. amegroups.com/article/view/10.21037/fomm-21-45/rc).

\section{Methods}

\section{Experimental model}

Experiments were performed under a project license (No. 00350-2019) granted by the Ethics Committee on Animal Use of the Araçatuba Dental School, jurisdiction granted by the National Board for the Control of Animal Experimentation (CONCEA), in accordance with national guidelines for the care and use of animals. Twenty-four male New Zealand rabbits, with body weight of 3 to $4 \mathrm{~kg}$ and 5 months old, underwent sinus floor lifting surgery and were divided into 4 groups according to the biomaterial used: group $1(\mathrm{G} 1 ; \mathrm{n}=6)$ received autogenous bone; group $2(\mathrm{G} 2 ; \mathrm{n}=6)$ received Cerabone ${ }^{\circledR}$ (Straumann ${ }^{\circledR}$ Group, Basel, Switzerland); group $3(\mathrm{G} 3 ; \mathrm{n}=6)$ received Cerabone ${ }^{\circledR}$ submitted to the sonication process; group $4(\mathrm{G} 4 ; \mathrm{n}=6)$ received Cerabone ${ }^{\circledR}$ associated with raloxifene submitted 
Table 1 Experimental groups according to the graft material

\begin{tabular}{lcccc}
\hline Groups & Autogenous & Cerabone & Sonication & Raloxifene \\
\hline G1 $(n=6)$ & $\checkmark$ & $x$ & $x$ & X \\
G2 $(n=6)$ & $x$ & $\checkmark$ & $\checkmark$ & $x$ \\
G3 $(n=6)$ & $x$ & $\checkmark$ & $\checkmark$ & $\checkmark$ \\
G4 $(n=6)$ & $x$ & $\sqrt{ }$ \\
\hline
\end{tabular}
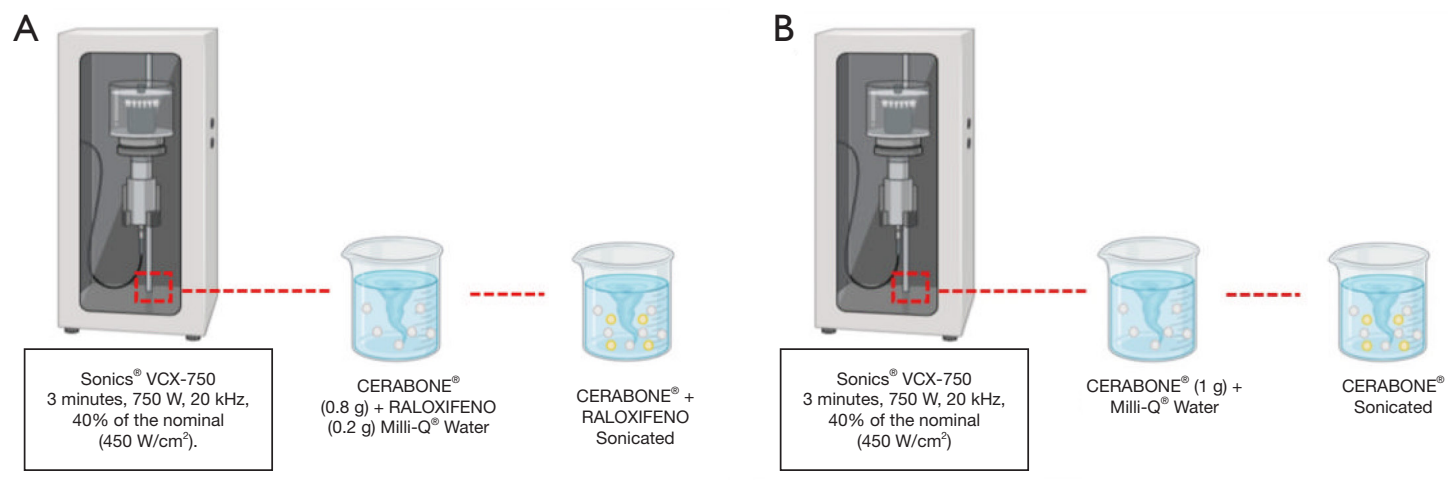

Figure 1 Sonication process of Cerabone. (A) Sonication of Cerabone with raloxifene used in group G4; (B) sonication of pure Cerabone used in group G3.

to sonication (Table 1). The biomaterials were employed by the operator in the sinuses of the rabbits in a randomized manner. The animals were kept confined in appropriate cages individually for their proper conditioning, in an environment with a controlled temperature of 21 to $22{ }^{\circ} \mathrm{C}$, with access to feed and water ad libitum. Professionals took care of the animals for the full period of the experiment, monitoring possible wounds, pain and infection. At 14 and 42 days after the sinus lift surgery, the animals were euthanized to collect samples for immunohistochemical and histomorphometric analyses.

\section{Biomaterial preparation}

The protocol employed for the preparation and characterization of the biomaterial (Cerabone ${ }^{\circledR}$ Sonicated) was the one established by Gomes-Ferreira \& LisboaFilho, so that the proportion of raloxifene was defined based on previous studies of the same authors (16). For Cerabone ${ }^{\circledR}$ sonication, raloxifene was associated to a proportion of $20 \%$ of the total volume (Group 4). For each $1 \mathrm{~g}$ of prepared material the following proportion was used: $0.8 \mathrm{~g}$ of Cerabone ${ }^{\circledR}$ and $0.2 \mathrm{~g}$ of raloxifene in its solid form. The two components were subjected to ultrasonic processing (Figure 1A). A Sonics ${ }^{\circledR}$ VCX-750 device (Sonics $\&$ Materials, Inc., USA) was used, for about 3 minutes, with $750 \mathrm{~W}$ power, $20 \mathrm{kHz}$ frequency and $40 \%$ of the nominal amplitude of the equipment $\left(450 \mathrm{~W} / \mathrm{cm}^{2}\right)$. To obtain a homogeneous system and have the particle size reduced, Milli-Q ${ }^{\circledR}$ (Millipore, USA) ultrapure water was used. After ultrasonic processing, the samples were left to dry at $60{ }^{\circ} \mathrm{C}$ for a period of 8 hours and were sterilized using ultraviolet radiation. For Cerabone ${ }^{\circledR}$ sonication (group 3), the same ultrasonic processing was performed without the presence of raloxifene (Figure 1B). After the ultrasonic procedure, the grafts were properly stored in a sterile recipient so that they could be used for sinus bone augmentation in the rabbits of G3 (Figure 2A) and G4 groups (Figure 2B).

\section{Surgical procedures}

To perform the surgical procedure, after 8 hours of fasting, all the animals were anesthetized by intramuscular injection of xylazine (Dopaser ${ }^{\circledR}$, Laboratory of Brazil Ltd., São Paulo, Brazil) at $6 \mathrm{mg} / \mathrm{kg}$ and ketamine $\left(\right.$ Vetaset $^{\circledR}$, Fort Dodge, Saúde Animal LTDA, Campinas, Brazil) at $10 \mathrm{mg} / \mathrm{kg}$. 

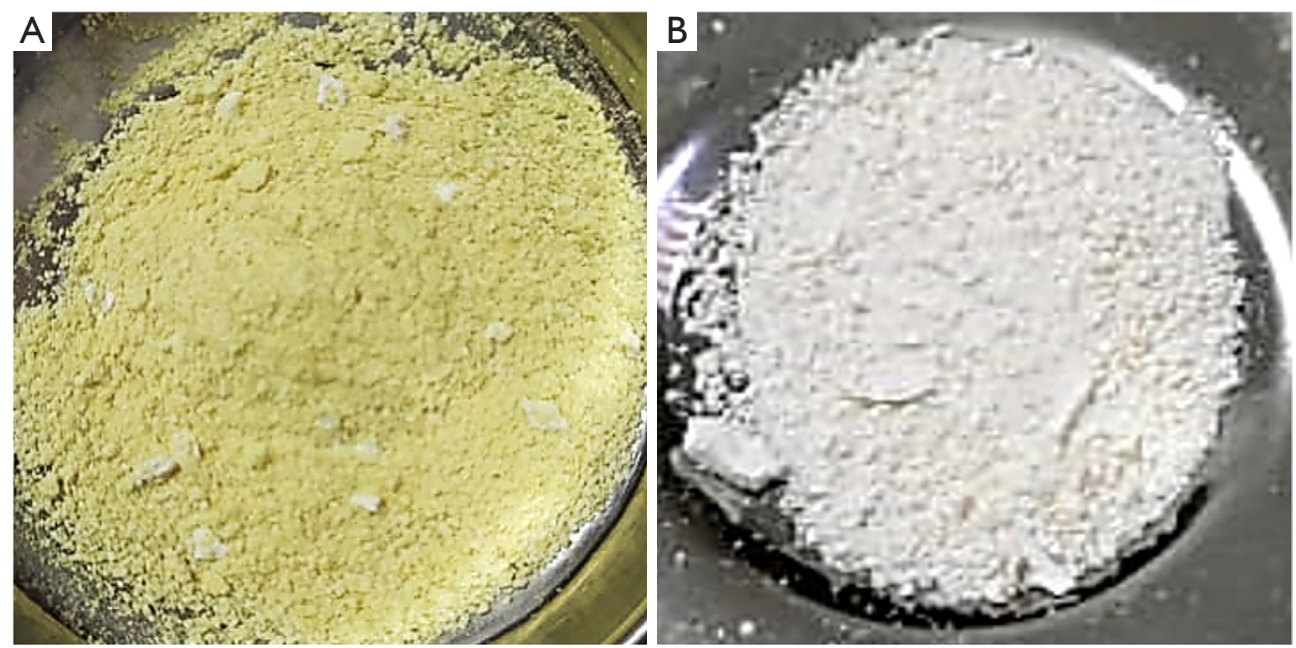

Figure 2 Heterogeneous graft. (A) Cerabone after ultrasonic processing with raloxifene; (B) cerabone after ultrasonic processing.

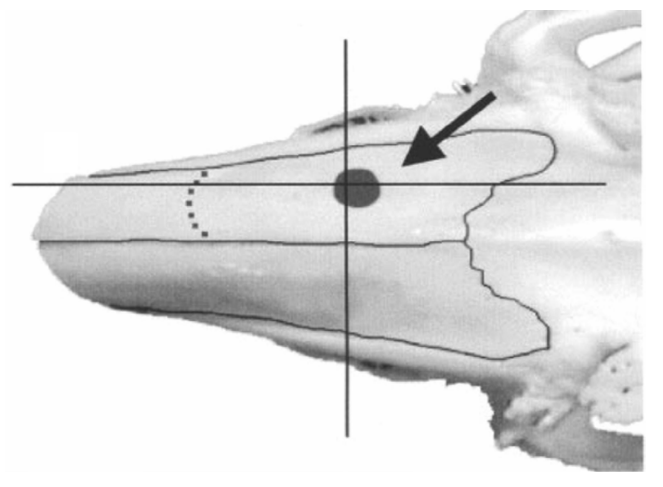

Figure 3 Outline of the experimental method in the axial plane of the rabbit's nose. The arrow indicates fenestration on the dorsal surface of the nose (arrow). Adapted from Asai et al. (17).

Anesthetic complementation with infiltration of $2 \%$ Mepivacaine Hydrochloride solution with epinephrine 1:100,000 (Mepiadre $100^{\circledR}$, DFL LTDA, Rio de Janeiro, Brazil) at a dose of $0.3 \mathrm{~mL} / \mathrm{kg}$ was performed in the midline of the nasal dorsum and in the tibial metaphysis in G1 animals, where the autogenous bone for grafting was collected. Preparation of the surgical site was performed on the tibial metaphysis and nasal dorsum of the animals with trichotomy and antisepsis with $10 \%$ degerming polyvinyl pyrrolidone iodine.

To access the tibial metaphysis, a $3-\mathrm{cm}$ incision was made in parallel to the long axis of the right tibia, subsequently the soft tissues were divulsioned and the bone tissue was exposed, and then the bone particles were collected using a bone scraper (Neodent ${ }^{\circledR}$, Curitiba, Paraná, Brazil), muscles and periosteum were repositioned (17).

To access the sinus cavity, a $50-\mathrm{mm}$ linear incision was made in the midline of the animal's nasal dorsum. The skin and periosteum will be carefully detached to provide exposure of the nasal bone and internasal suture. Subsequently to exposure, a circular window with a diameter of $5 \mathrm{~mm}$ was performed bilaterally to the midline of the nasal dorsum, approximately $20 \mathrm{~mm}$ before the nasofrontal suture and $10 \mathrm{~mm}$ laterally to the midline, using a 5-mm diameter trephine drill used for demarcation of the area (Figure 3) and a spherical diamond drill No. 1011 (KG Sorensen ${ }^{\circledR}$, Cotia, São Paulo, Brazil) to finish the osteotomies, both mounted on a 20:1 (Kavo ${ }^{\circledR}$ do Brasil, Joinvile, Brazil), connected to an electric motor controlled rotation (model BLM 600 plus, Driller ${ }^{\circledR}$, Jaguaré, São Paulo, Brazil) at a speed of $1,500 \mathrm{rpm}$. During the procedure, irrigation was performed with sterile $0.9 \%$ saline solution (Darrow, Rio de Janeiro, Brazil). Once the window was made in the maxillary sinus, the sinus membrane was detached and elevated with the use of special curettes (Neodent ${ }^{\circledR}$, Curitiba, Paraná, Brazil). Once the surgical sites had been prepared, the grafts were then packed, according to the distribution in the groups (G1, G2, G3, G4), in a randomized, blinded manner. An amount of $0.33 \mathrm{~g}$ should be placed in each maxillary sinus by experimental procedure (18). The repositioning of the muscles and periosteum was performed with 5-0 Polyglactin 910 thread (Vicryl 5-0 ${ }^{\circledR}$, Ethicon, Johnson \& Johnson, São José dos Campos, Brazil) through simple interrupted sutures, and for the skin 5-0 nylon thread (Ethilon 5-0, Ethicon Johnson \& 

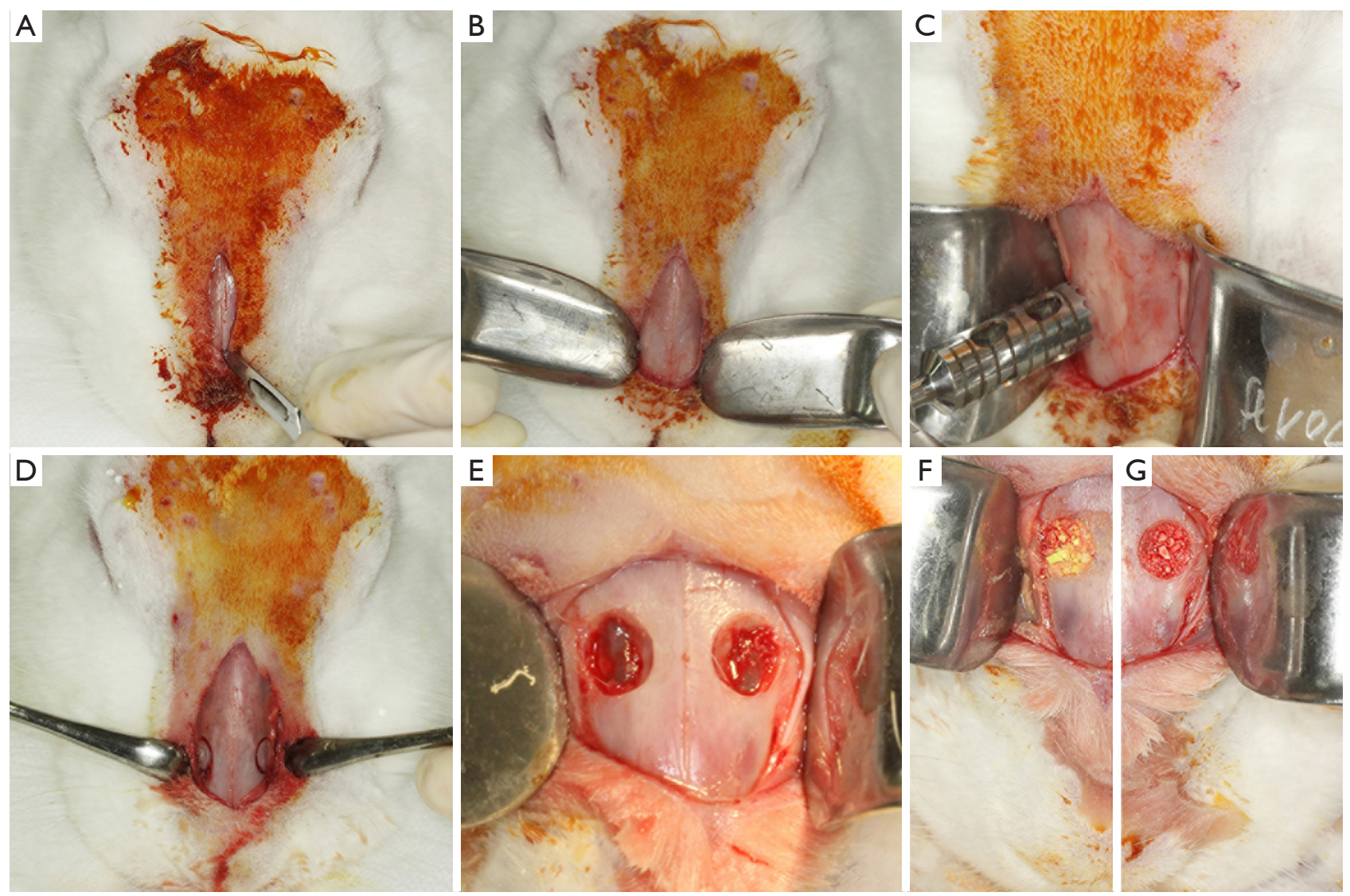

Figure 4 Surgical procedure for maxillary sinus elevation. (A) Incision; (B) exposure of the surgical site; (C-E) window demarcation and maxillary sinus membrane detachment; (F) affixing group 4 material; (G) affixing group 3 material.

Johnson) was used (Figure 4).

After the procedure, the animals received an intramuscular dose of 20,000 IU of penicillin G benzathine (Pentabiotic, Veterinário Pequeno Porte, Fort Dodge Animal Health Ltd., Campinas, Brazil) and $1 \mathrm{mg} / \mathrm{kg} / \mathrm{day}$ of dipyrone sodium. After a period of 14 and 42 days the animals were euthanized by anesthetic overdose.

\section{Histological processing}

The animals were euthanized at 14 and 42 days after sinus grafting using anesthetic overdose. Maxillary sinus samples were collected and fixed in $10 \%$ formaldehyde (Reagentes analíticos, Dinâmica Odonto-hospitalar Ltda, Catanduva, São Paulo, Brazil) for 48 hours, washed in tap water for 24 hours and then demineralized in 10\% EDTA solution. The samples were dehydrated in an increasing sequence of alcohols and diaphanized in xylene. The samples were then embedded in paraffin. Sections 5 - $\mu$ m thick in the coronal direction of the maxillary sinus were obtained and mounted on histological slides, which were submitted to immunohistochemical processing and hematoxylin and eosin staining for histomorphometric analysis.

\section{Immunobistochemical analysis}

The immunoperoxidase detection method was used. The paraffin sections were selected for immunolabeling against vascular endothelial growth factor (VEGF), alkaline phosphatase (ALP), osteocalcin (OCN), tartrate resistant acid phosphatase (TRAP) and receptor activator of nuclear factor kappa-B ligand (RANKL) proteins (Santa Cruz Biotechnology, Dallas, TX, USA). Initially we performed deparaffinization (sections were kept in an oven for 20 minutes, followed by baths in CitriSolv and baths in decreasing concentrations of alcohols, ending with the hydration of the sections immersed in PBS $(0.01 \mathrm{M}$ phosphate buffered saline). Endogenous peroxidase activity 
was inhibited with hydrogen peroxide, and in the next step, the slides underwent antigenic recovery with citrate phosphate buffer ( $\mathrm{pH}$ 6.0) in moist heat. Endogenous biotin was also blocked with skim milk for 20 minutes. Also, as a method to block nonspecific staining, the primary antibody was prepared in a $1 \%$ phosphate buffer and bovine albumin solution. Polyclonal primary antibodies produced from goats against VEGF (SC 1881, Santa Cruz Biotechnology, Dallas, TX, USA) and ALP (PDLIM3, Santa Cruz Biotechnology, Dallas, TX, USA) were used in the 14-day samples; primary antibodies against OCN (SC365797, Santa Cruz Biotechnology, Dallas, TX, USA), TRAP (SC30832, Santa Cruz Biotechnology, Dallas, TX, USA) and RANKL (12A380, Santa Cruz Biotechnology, Dallas, TX, USA) for the 42-day samples. Goat biotinylated polyclonal secondary antibody (Pierce Biotechnology, Waltham, MA, USA) was used. The signal from the reaction was amplified by incubation in avidin and biotin (ABC standard kit, Vector Laboratories, Burlingame, CA, USA) and the reaction was revealed using diaminobenzidine (Dako Laboratories, Santa Clara, CA, USA). At the end of the immunohistochemical reactions, counterstaining was performed with Harris hematoxylin. Then, the slides were dehydrated in xylene and coverslips were mounted over the sections.

The immunostaining analysis was performed by assigning scores according to the area of positive presence of the proteins in the repair tissue (area of interest). For $25 \%$ of positive immunostaining, score 1 will be attributed; for $50 \%$ score 2 ; and for $75 \%$ score 3 . The objective of the immunohistochemical analysis was to characterize the dynamics of the events related to bone repair, by showing the osteoconduction of the biomaterial through the VEGF protein at 14 days and the initial mineralization of the neoformed bone tissue through the precipitation of phosphate ions represented by ALP. RANKL and TRAP are indicative of bone resorption in reparative tissue. Osteocalcin, being a late expressed protein, characterizes calcium deposition in extracellular matrix.

\section{Histomorphometric analysis}

Two slices from each animal were stained with hematoxylin and eosin for morphometric analysis. Five regions of each maxillary sinus sample were digitally captured at $\times 20$ magnification (Leica DMLB, Heerbrugg, Switzerland) and blindly analyzed by an expert observer. An ImageJ software tool was used to perform the morphometry, which contained 391 points on a template of 8,000 pixels. Points corresponding to the neoformed bone tissue, the remaining biomaterial and the adjacent connective tissue were summed and the total of each variable was obtained. The results between groups were analyzed by analysis of variance (ANOVA) followed by a Tukey post hoc test when necessary. The significance level was set at $\mathrm{P}<0.05$.

\section{Statistical method}

The GraphPad Prism 9.0.0 software was used for the statistical analysis. Homoscedasticity was analyzed with the Shapiro-Wilk test. The one-way ANOVA test was used to evaluate the histomorphometric analysis measurements, as well as the Tukey post-test, when necessary. The level of significance was set at $\mathrm{P}<0.05$.

\section{Sample size}

The sample size calculation was defined from the data of a study on sinus floor elevation in rabbits. In this experiment 16 rabbits were divided into 4 groups with 4 rabbits in each. A comparison was made between antrostomy and repositioning of the bone window and the use of a collagen membrane on the opposite window. A $10 \%$ difference in bone formation was observed in the bone window that was repositioned, with a low standard deviation. In another study by Amari et al. 2020 (19), in which they performed bone window displacement in rabbit sinuses, 6 animals per group were used to evaluate with microtomographic and histometric analysis the bone formation in sinus cavities. In this study the power of the test was calculated, where a power of 0.8 and a type 1 error of 0.05 were obtained. Based on these experiments, we calculated that 6 animals per group would be sufficient to show differences in the present study.

\section{Results}

At the end of the experiment (14- and 42-day post-operative periods), all animals were in good health, keeping their body weight around $4 \mathrm{~kg}$. All samples were analyzed by both immunohistochemical and histomorphometric analysis, so that an $n=6$ was achieved for the periods included in the experiment.

\section{Immunobistochemical analysis}

Different markers were evaluated at 14 (Table 2; Figure 5) 
Table 2 Scores of immunolabeling for VEGF and ALP proteins in different experimental groups at 14 days postoperative

\begin{tabular}{lcccc}
\hline Proteins & G1 & G2 & G3 & G4 \\
\hline VEGF & 2 & 1 & 2 & 2 \\
ALP & 2 & 2 & 2 & 2 \\
\hline
\end{tabular}

VEGF, vascular endothelial growth factor; ALP, alkaline phosphatase.
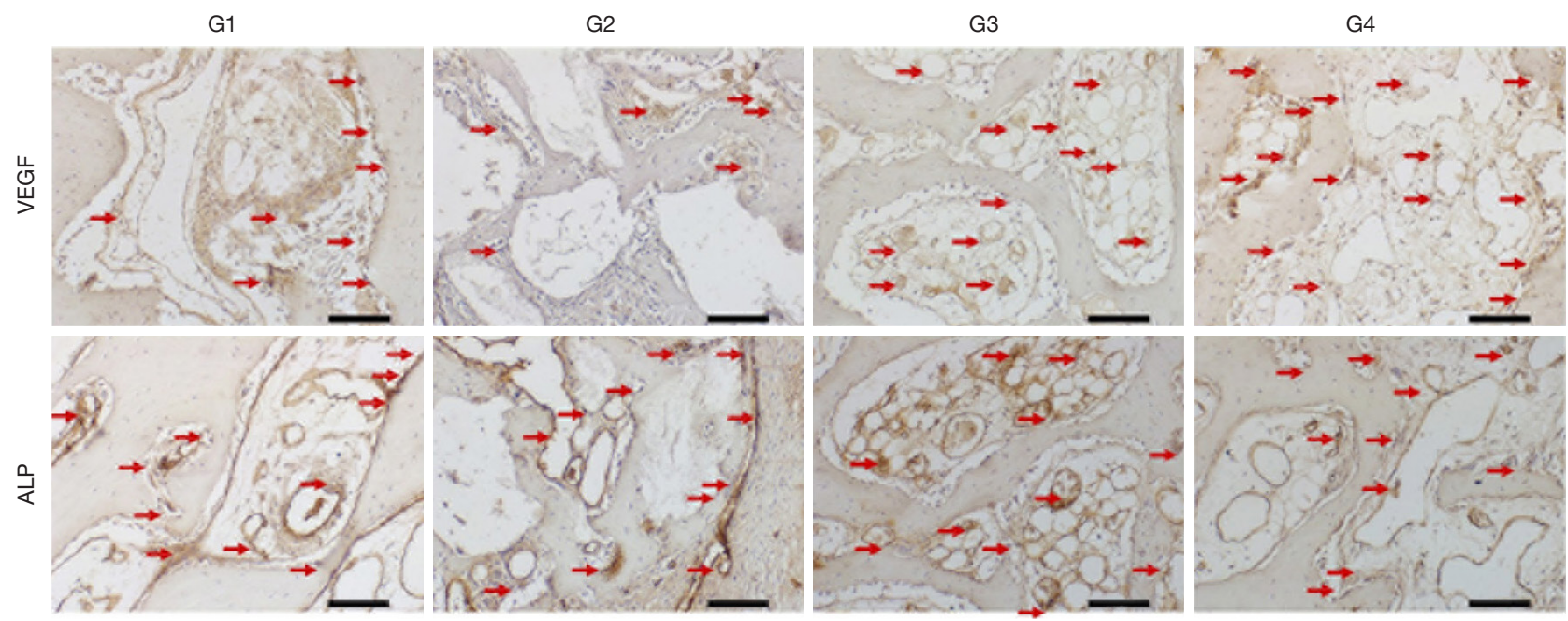

Figure 5 Immunohistochemical using VEGF and ALP proteins at 14 days. Immunolabelling of these proteins in G1, G2, G3 and G4 groups (original, $\times 25$ ). Immunolabelling was defined as: mild; moderate and intense. The red arrows show the immunolabelling of proteins in the extracellular matrix. VEGF, vascular endothelial growth factor; ALP, alkaline phosphatase.

and 42 days (Table 3; Figure 6) in order to label different events that are important for bone formation. The expression of VEGF indicates the osteoconductive potential of the graft used, since it is related to the proliferation of blood vessels necessary for the nutrition of the neoformed bone tissue.

At 14 days, the VEGF present in osteoblasts was evaluated in all experimental groups. In the G1 group, moderate labeling of this growth factor was observed in the osteoblast lineage cells. In group G2, a discrete marking of VEGF was observed, observed near particles of the biomaterial. In group G3, moderate immunolabeling of VEGF was observed, especially in the osteoblast lineage cell. Group G4 showed moderate immunolabeling for VEGF, showing an important activity of the osteoblast lineage cells with positive presence of this growth factor.

The ALP was evaluated in order to characterize the cells of the osteoblast lineage, as well as the mineralization activity at the initial point. This protein is related to the beginning of mineralization of the newly formed bone tissue, with precipitation of phosphate ions on the bone matrix, and its presence indicates a better-quality bone tissue by improving the hydroxyapatite crystals. The group filled with autogenous bone (G1) showed a moderate ALP staining, showing an important mineralization process in the 14-day period. In the G2 group, moderate ALP labeling was observed, especially near the biomaterial particles. The osteoblastic lineage cells also showed positive labeling. In groups G3 and G4, a similar pattern of immunolabeling was observed, but with higher expression in group G3. Positive labeling was observed in the medullary space, with intense labeling of the cells in this area. In group G4, moderate expression was observed in the medullary space, marking osteoblasts positively.

At 42 days, immunolabeling of proteins related to the final stages of the repair process was observed. RANKL, which is a novel member of the tumor necrosis factor (TNF) family showed mild immunolabeling in G1, representing low signaling for the resorption activity that is driven by RANKL expression. In the G4 group, areas with 
Table 3 Scores of immunolabeling for RANKL, TRAP and OCN proteins in different experimental groups at 42 days postoperative

\begin{tabular}{lcccc}
\hline Proteins & G1 & G2 & G3 & G4 \\
\hline RANKL & 1 & 3 & 2 & 2 \\
TRAP & 1 & 1 & 1 & 1 \\
OCN & 2 & 3 & 3 & 3 \\
\hline
\end{tabular}

RANKL, receptor activator of nuclear factor kappa-B ligand; TRAP, tartrate resistant acid phosphatase; OCN, osteocalcin.

G1

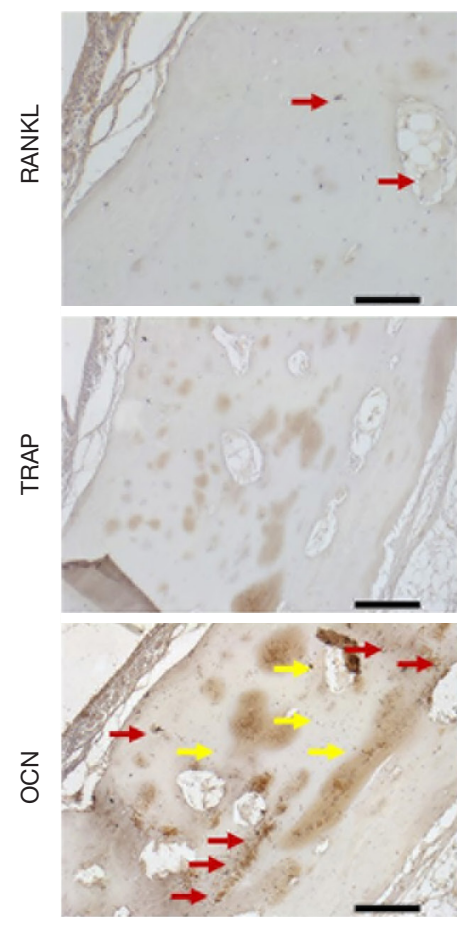

G2
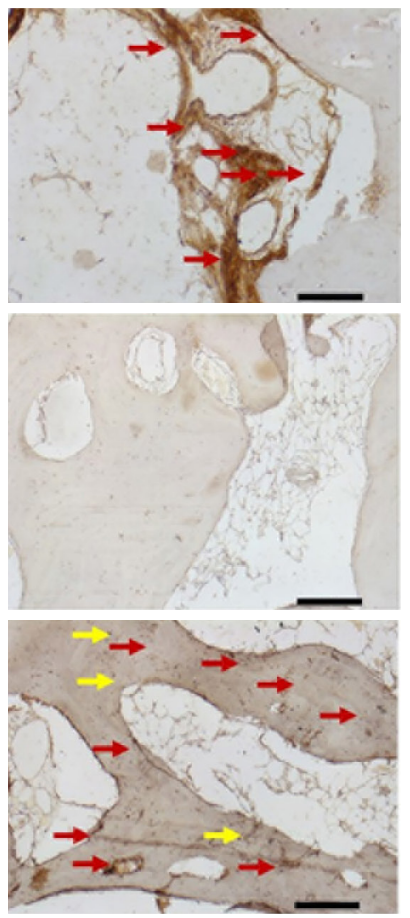

G3

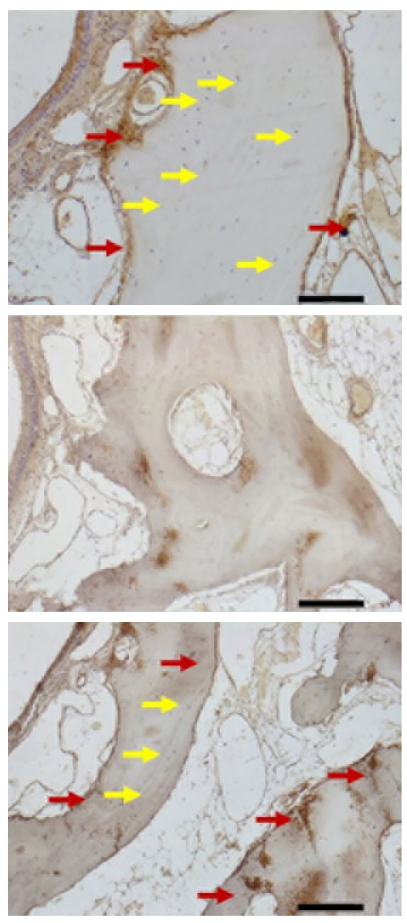

G4

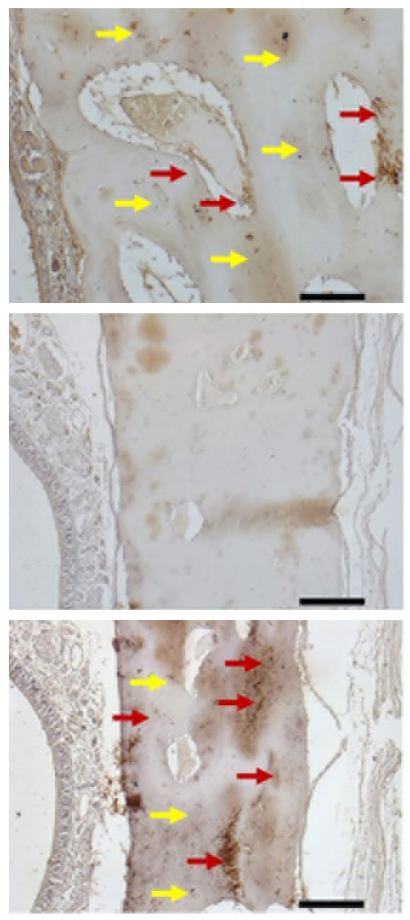

Figure 6 Immunohistochemical using RANKL, TRAP and OCN proteins at 42 days. Immunolabelling of these proteins in G1, G2, G3 and G4 groups (original, $\times 25$ ). Immunolabelling was defined as: mild; moderate and intense. The red arrows show the immunolabelling of proteins in the extracellular matrix. The yellow arrows show osteocytes trapped by the mineralized bone matrix. RANKL, receptor activator of nuclear factor kappa-B ligand; TRAP, tartrate resistant acid phosphatase; OCN, osteocalcin.

intense signaling for RANKL were observed, especially in medullary areas of the defect. Perhaps, this observation is related to the presence of the particles and the estimation for resorption activity to degrade the biomaterial remnants still present at this time. In the G3 group, moderate labeling for RANKL was observed. Importantly, in this group, positive RANKL labeling was also observed in osteocytes, presented in the repaired area. In group G4, a tissue with a higher level of maturity was observed than the other experimental groups G2 and G3, showing moderate expression for RANKL, distributed in osteocytes and some areas of osteoblast lineage cells in the medullary space.

TRAP which is a marker of resorption activity showed a mild/discrete labeling in all groups, showing a low resorption activity in this postoperative period.

On the other hand, OCN, which is a marker of mineralization, characterizing an aspect of maturity of the bone formed, showed moderate expression in the autogenous group. In the groups with Cerabone (G2, G3 and G4), an intense expression of osteocalcin was observed, indicating greater maturity of the bone tissue in the presence of this biomaterial. It was observed that the 
Table 4 Statistical results from histomorphometric evaluation after 14 days

\begin{tabular}{lccc}
\hline Experimental groups & New bone (\%) & Connective tissue (\%) & Remaining material (\%) \\
\hline G1 & $55.2 \pm 2.0^{*}$ & $45.0 \pm 2.3^{*}$ & $0 \pm 0^{\star}$ \\
G2 & $37.5 \pm 2.6^{*}$ & $38.4 \pm 2.5^{*}$ & $24.8 \pm 1.9^{\star}$ \\
G3 & $38.2 \pm 2.0^{*}$ & $41.6 \pm 2.7^{*}$ & $21.5 \pm 1.4^{*}$ \\
G4 & $50.1 \pm 2.7^{*}$ & $24.0 \pm 2.6^{*}$ & $25.9 \pm 2.3^{\star}$ \\
\hline
\end{tabular}

*, $P<0.05$.
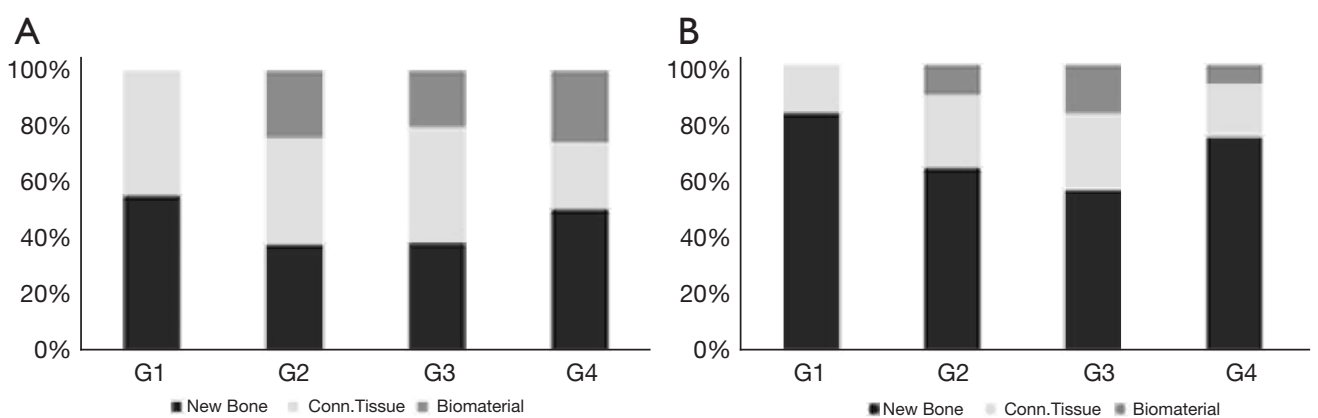

Figure 7 Graphic representation of histomorphometry. (A) Percent values of new bone, connective tissue and remaining biomaterial of the experimental groups after 14 days. (B) Percent values of new bone, connective tissue and remaining biomaterial of the experimental groups after 42 days.

characteristics of the bone formed in the defect area have a similar pattern among all groups and the osteocalcin labeling was very similar in all of them. This result shows that at 42 days all groups reached the same stage of bone formation in the defect area.

\section{Histomorphometric analysis}

In the 14-day postoperative period, a higher amount of neoformed bone tissue was observed in groups G1 (autogenous; 55.2 \pm 2.0 ) and G4 (Cerabone associated with raloxifene; $50.1 \pm 2.7$ ), both differing statistically from groups G2 (pure Cerabone; 37.5 \pm 2.6 ; G1 vs. G2: $\mathrm{P}=0.0001$; G4 vs. G2: $\mathrm{P}=0.0016)$ and $\mathrm{G} 3$ (sonicated Cerabone; 38.2 \pm 2.0 ; $\mathrm{G} 1$ vs. $\mathrm{G} 3: \mathrm{P}=0.0002 ; \mathrm{G} 4$ vs. $\mathrm{G} 3: \mathrm{P}=0.0023)$. Regarding adjacent connective tissue, greater amount was observed in G1 (45.0 \pm 2.3$)$, followed by the G3 group $(41.6 \pm 2.7)$ and G2 (38.4 \pm 2.5$)$. Less connective tissue was observed in G4 $(24.0 \pm 2.6)$, with a statistically significant difference from the other groups (G1 vs. G4: $\mathrm{P}<0.0001 ; \mathrm{G} 2$ vs. $\mathrm{G} 4: \mathrm{P}=0.0005$; G3 vs. G4: $\mathrm{P}=0.0001)$. No grafting was observed in $\mathrm{G} 1$. The largest amount of remaining biomaterial was found in
G4 (25.9 \pm 2.3$)$, followed by G2 $(24.8 \pm 1.9)$ and G3 $(21.5 \pm 1.4)$ (Table 4; Figure 7A).

At 42 days postoperatively, the amount of newly formed bone tissue increased by more than $20 \%$ in most groups. The opposite happened with the presence of connective tissue. This change in the pattern of bone repair suggests maturation of the tissue formed within the sinus cavity. Greater bone formation was found in the G1 group (83.5 \pm 2.2$)$, followed by the G4 group $(75.0 \pm 2.6$; G1 vs. G4: $\mathrm{P}=0.0189$ ), which in turn showed $11 \%$ more neoformed bone than the G2 group (64. $2 \pm 2.9$; G1 vs. G2: $\mathrm{P}<0.0001$; $\mathrm{G} 4$ vs. $\mathrm{G} 2: \mathrm{P}=0.0048)$ and $19 \%$ more than $\mathrm{G} 3(56.7 \pm 2.8$; $\mathrm{G} 1$ vs. $\mathrm{G} 3: \mathrm{P}<0.0001 ; \mathrm{G} 4$ vs. $\mathrm{G} 3: \mathrm{P}=0.0001 ; \mathrm{G} 2$ vs. $\mathrm{G} 3$ : $\mathrm{P}=0.0369)$. Less connective tissue was observed in the $\mathrm{G} 1$ group (16.7 \pm 2.8$)$, differing statistically from G2 $(25.7 \pm 2.6$; $\mathrm{P}=0.0228)$ and $\mathrm{G} 3(27.2 \pm 3.2 ; \mathrm{P}=0.0099)$. Similar to $\mathrm{G} 1$, the G4 group showed less connective tissue $(19.1 \pm 3.0)$ when compared to G2 and G3, differentiating statistically from G3 $(\mathrm{P}=0.0382)$. The largest amount of remaining biomaterial was found in $G 3(16.6 \pm 3.0)$, statistically different from $\mathrm{G} 1(0 \pm 0 ; \mathrm{P}=0.0002)$ and $\mathrm{G} 4(6.6 \pm 2.8$; $\mathrm{P}=0.0059)($ Table 5; Figure 7B). 
Table 5 Statistical results from histomorphometric evaluation after 42 days

\begin{tabular}{lccr}
\hline Experimental groups & New bone (\%) & Connective tissue (\%) & Remaining material (\%) \\
\hline G1 & $83.5 \pm 2.2^{*}$ & $16.7 \pm 2.8^{*}$ & $0 \pm 0^{*}$ \\
G2 & $64.2 \pm 2.9^{*}$ & $25.7 \pm 2.6^{*}$ & $10.5 \pm 2.9^{*}$ \\
G3 & $56.7 \pm 2.8^{*}$ & $27.2 \pm 3.2^{*}$ & $16.6 \pm 3.0^{*}$ \\
G4 & $75.0 \pm 2.6^{*}$ & $19.1 \pm 3.0^{*}$ & $6.6 \pm 2.8^{*}$ \\
\hline
\end{tabular}

${ }^{*}, \mathrm{P}<0.05$.

\section{Discussion}

The reduction of bone repair time and improvement in the quality of the newly formed bone are the main focuses of the dental industry when it comes to biomaterials for bone reconstructions. It is known that bone quantity and quality are determining factors for the primary and biological stability of osseointegrated implants, and that they directly impact the success of oral rehabilitations (20). Thus, the search for biomaterials that aid in the gain of maxillomandibular bone tissue is of fundamental importance for the advancement of clinical and dental practices, especially in the field of implantology.

One point should be considered regarding the animals used in this study. Animal models are considered the first choice for preclinical testing of productions that seek to improve bone repair (21). Rabbits were selected here because of their maxillary sinus model, because they have similar characteristics to human maxillary sinuses, and because they allow the reproduction of maxillary sinus elevation as well as its grafting (22). However, bone healing in rabbits can be completed quickly, given a high metabolic rate that is higher than that found in humans. Thus, at 42 days it is possible to observe bone repair well consolidated in rabbits (23).

The histomorphometric results showed a better performance of the group in which Cerabone associated with raloxifene was used (G4). A greater amount of bone neoformation inside the sinus cavity was detected, showing that the purpose of using this biomaterial was achieved. This result supports the immunohistochemical findings, which showed important biological characteristics of the graft in question, such as osteoconductive potential, deposition of hydroxyapatite crystals, balanced resorption activity, resulting in a mature and mineralized bone tissue at 42 days.

The choice of using Cerabone as biomaterial was based on the lack of published scientific studies evaluating its performance on the sinus floor augmentation in rabbits. Cerabone is a biomaterial basically composed of hydroxyapatite, and has a slow degradation after its application (15). This idea justifies the presence of the remaining biomaterial inside the sinus cavity at 42 days. However, in this study, Cerabone alone was not effective in promoting additional bone neoformation, as can be noted in the results obtained by groups G2 (64\%) and G3 (56\%) from histomorphometric analysis, being significantly lower than groups G1 (83\%) and G4 (75\%). Although the histometric findings were not favorable, a higher expression of osteocalcin at 42 days was noted in all groups in which Cerabone was used, indicating that despite the deficient bone formation, the biomaterial contributed to the maturation and mineralization of the bone tissue formed inside the sinus cavity, which can be attributed to the action of the hydroxyapatite present in the composition.

Raloxifene, a selective estrogen receptor modulator used for the treatment of post-menopausal osteoporosis, plays a role in the regulation of osteoblastic lineage cells and bone remodeling $(24,25)$. Some studies have demonstrated the beneficial effect of systemic raloxifene on alveolar and periimplant repair in ovariectomized rats (7). In addition, the local action of raloxifene in a proportion of $20 \%$ associated with $80 \%$ of an alloplastic biomaterial promoted bone formation and improved microarchitecture in rat periimplant defects (6). The description of the favorable results obtained from the evaluation of raloxifene on bone repair justified the use of this drug in our evaluation of sinus floor elevation in rabbits. Corroborating previously published studies, we observed that the action of raloxifene led to an improvement in the properties of Cerabone, since this biomaterial, when associated with the drug, promoted significant bone formation within the sinus cavity, so that the results obtained by the G4 group were superior to the groups in which Cerabone was used alone. In another study using raloxifene implants associated with chitosan and chitosan with bioglass in rat tibial bone 
defects, it was demonstrated that the compound formed by chitosan and raloxifene was able to improve bone repair after 12 weeks in comparison with untreated bone defects and those containing only bioglass, which could require more time to exert its effect on bone repair (26), a fact that may also be associated with the results found here with the use of Cerabone biomaterial given its resorption and replacement process by bone tissue. Formulations that take a longer time to reach a peak of result may be interesting for approaches to extensive bone lesions, which will require a longer time for healing and consequently need a greater mechanical bone support that can be presented by these formulations.

The construction of a scaffold capable of supporting an extracellular matrix, serving as a favorable site for bone cell proliferation and tissue regeneration is the proposal of this study. Presumably, nanoscale cavities were made in the bovine graft (Cerabone) using an ultrasonic device (Sonics ${ }^{\circledR}$ VCX-750). These cavities serve as a support for the raloxifene particles, so that, the graft will be covered by a layer of raloxifene. The slow degradation of the biomaterial used (Cerabone) in the long term can allow excellent mechanical stability. However, it may hinder the action of raloxifene in the short term, which may corroborate for the realization of studies with a longer experimental period.

\section{Conclusions}

In view of the results obtained in this experiment, we can conclude that Cerabone when subjected to ultrasonic processing in combination with raloxifene can lead to favorable bone formation when compared to using Cerabone in an isolated manner. However, future in vitro studies are needed to evaluate this combination for further clinical evaluation.

\section{Acknowledgments}

Funding: This work was supported by Coordination for Higher Education Staff Development-CAPES [001].

\section{Footnote}

Provenance and Peer Review: This article was commissioned by the Guest Editors (Valfrido Antônio Pereira-Filho and Pedro Carvalho) for the series "Xenogenous and Xenosynthetic Bone Substitutes: State-of-the-art and Clinical
Outcomes" published in Frontiers of Oral and Maxillofacial Medicine. The article has undergone external peer review.

Reporting Checklist: The authors have completed the ARRIVE reporting checklist. Available at https://fomm. amegroups.com/article/view/10.21037/fomm-21-45/rc

Data Sharing Statement: Available at https://fomm. amegroups.com/article/view/10.21037/fomm-21-45/dss

Conflicts of Interest: All authors have completed the ICMJE uniform disclosure form (available at https://fomm. amegroups.com/article/view/10.21037/fomm-21-45/ coif). The series "Xenogenous and Xeno-synthetic Bone Substitutes: State-of-the-art and Clinical Outcomes" was commissioned by the editorial office without any funding or sponsorship. The authors have no other conflicts of interest to declare.

Ethical Statement: The authors are accountable for all aspects of the work in ensuring that questions related to the accuracy or integrity of any part of the work are appropriately investigated and resolved. Experiments were performed under a project license (No. 00350-2019) granted by the Ethics Committee on Animal Use of the Araçatuba Dental School, jurisdiction granted by the National Board for the Control of Animal Experimentation (CONCEA), in accordance with national guidelines for the care and use of animals.

Open Access Statement: This is an Open Access article distributed in accordance with the Creative Commons Attribution-NonCommercial-NoDerivs 4.0 International License (CC BY-NC-ND 4.0), which permits the noncommercial replication and distribution of the article with the strict proviso that no changes or edits are made and the original work is properly cited (including links to both the formal publication through the relevant DOI and the license). See: https://creativecommons.org/licenses/by-nc$\mathrm{nd} / 4.0 \%$.

\section{References}

1. Testori T, Weinstein T, Scutellà F, et al. Implant placement in the esthetic area: criteria for positioning single and multiple implants. Periodontol 2000 2018;77:176-96.

2. Block MS, Kent JN. Sinus augmentation for dental 
implants: the use of autogenous bone. J Oral Maxillofac Surg 1997;55:1281-6.

3. Crespi R, Vinci R, Capparè P, et al. Calvarial versus iliac crest for autologous bone graft material for a sinus lift procedure: a histomorphometric study. Int J Oral Maxillofac Implants 2007;22:527-32.

4. Gerressen M, Hermanns-Sachweh B, Riediger D, et al. Purely cancellous vs. corticocancellous bone in sinus floor augmentation with autogenous iliac crest: a prospective clinical trial. Clin Oral Implants Res 2009;20:109-15.

5. Sbordone L, Toti P, Menchini-Fabris G, et al. Implant success in sinus-lifted maxillae and native bone: a 3-year clinical and computerized tomographic follow-up. Int J Oral Maxillofac Implants 2009;24:316-24.

6. Lisboa-Filho PN, Gomes-Ferreira PHS, Batista FRS, et al. Bone repair with raloxifene and bioglass nanoceramic composite in animal experiment. Connect Tissue Res 2018;59:97-101.

7. Ramalho-Ferreira G, Faverani LP, Momesso GAC, et al. Effect of antiresorptive drugs in the alveolar bone healing. A histometric and immunohistochemical study in ovariectomized rats. Clin Oral Investig 2017;21:1485-94.

8. Bang JH, Suslick KS. Applications of ultrasound to the synthesis of nanostructured materials. Adv Mater 2010;22:1039-59.

9. Arruda LB, Orlandi MO, Lisboa-Filho PN. Morphological modifications and surface amorphization in $\mathrm{ZnO}$ sonochemically treated nanoparticles. Ultrason Sonochem 2013;20:799-804.

10. Mason TJ, Cobley AJ, Graves JE, et al. New evidence for the inverse dependence of mechanical and chemical effects on the frequency of ultrasound. Ultrason Sonochem 2011;18:226-30.

11. Roumiani ME, Dorosti N. Sonochemical synthesis of a nanodandelion tin(IV) complex with carbacylamidophosphate ligand as anti-Alzheimer agent: Molecular docking study. Ultrason Sonochem 2019;55:207-16.

12. Tawil G, Barbeck M, Unger R, et al. Sinus Floor Elevation Using the Lateral Approach and Window Repositioning and a Xenogeneic Bone Substitute as a Grafting Material: A Histologic, Histomorphometric, and Radiographic Analysis. Int J Oral Maxillofac Implants 2018;33:1089-1096.

13. Călin DL, Rusu A, Mitrea M. Sinus lift using a mixture of a-prf and cerabone and simultaneous insertion of a single implant. Romanian Journal of Oral Rehabilitation 2016;8:66-74.

14. Puišys A, Žukauskas S, Kubilius R, et al. Bone augmentation and simultaneous soft tissue thickening with collagen tissue matrix derivate membrane in an aesthetic area. A case report. Stomatologija 2017;19:64-8.

15. Nikoghosyan AS, Ting H, Shen J, et al. Dielectric Anisotropy of Human Bone and CERABONE® in the Terahertz Spectral Range 0.2 to 2.5 THz. J Phys Conf Ser 2017;826:012005

16. Gomes-Ferreira PHS, Lisboa-Filho PN, da Silva AC, et al. Sonochemical time standardization for bioactive materials used in periimplantar defects filling. Ultrason Sonochem 2019;56:437-46.

17. Asai S, Shimizu Y, Ooya K. Maxillary sinus augmentation model in rabbits: effect of occluded nasal ostium on new bone formation. Clin Oral Implants Res 2002;13:405-9.

18. Duailibe de Deus CB, Garcia Júnior IR. Regeneração óssea após elevação do assoalho do seio maxilar de coelhos com hidroxiapatita e beta-tricálcio fosfato em grânulos e pasta: análise tomográfica, microtomográfica, histológica, histomorfométrica e imunoistoquímica. Araçatuba 2018:92.

19. Amari Y, Botticelli D, Apaza Alccayhuaman KA, et al. The Influence on Healing of Bony Window Elevated Inward in the Sinus Cavity as Cortical Bone Graft: A Histomorphometric Study in Rabbit Model. Int J Oral Maxillofac Implants 2020;35:879-87.

20. Javed F, Ahmed HB, Crespi R, et al. Role of primary stability for successful osseointegration of dental implants: Factors of influence and evaluation. Interv Med Appl Sci 2013;5:162-7.

21. Peric M, Dumic-Cule I, Grcevic D, et al. The rational use of animal models in the evaluation of novel bone regenerative therapies. Bone 2015;70:73-86.

22. Dam C, Jung UW, Park KM, et al. Effect of teriparatide on early sinus graft healing in the ovariectomized rabbit. Clin Oral Implants Res 2020;31:264-73.

23. Roberts WE, Turley PK, Brezniak N, et al. Implants: Bone physiology and metabolism. CDAJ 1987;15:54-61.

24. Ramalho-Ferreira G, Faverani LP, Grossi-Oliveira GA, et al. Alveolar bone dynamics in osteoporotic rats treated with raloxifene or alendronate: confocal microscopy analysis. J Biomed Opt 2015;20:038003.

25. Kavas A, Keskin D, Altunbaş K, et al. Raloxifene-/ raloxifene-poly(ethylene glycol) conjugate-loaded 
microspheres: A novel strategy for drug delivery to bone forming cells. Int J Pharm 2016;510:168-83.

26. Abdel-Salam FS, Elkheshen SA, Mahmoud AA, et al. In-situ forming chitosan implant-loaded with raloxifene

doi: $10.21037 /$ fomm-21-45

Cite this article as: de Siqueira NB, Ervolino da Silva AC, Pereira RDS, Hochuli-Vieira E, Lisboa-Filho PN, Duailibe de Deus CB, Okamoto R. Different responses of heterogeneous graft presentations in bone reconstructions during sinus lift elevation surgery: an immunolabeling and histomorphometric study performed in rabbits. Front Oral Maxillofac Med 2022;4:1. hydrochloride and bioactive glass nanoparticles for treatment of bone injuries: Formulation and biological evaluation in animal model. Int $\mathrm{J}$ Pharm 2020;580:119213. 